\title{
UNIVERSITYOF BIRMINGHAM

\section{Attenuation of UVR-induced vitamin D3 synthesis in a mouse model deleted for keratinocyte lathosterol 5-desaturase}

\author{
Makarova, Anastasia M.; Pasta, Saloni; Watson, Gordon; Shackleton, Cedric; Epstein, Ervin
} $\mathrm{H}$.

DOI:

10.1016/j.jsbmb.2017.03.017

License:

Creative Commons: Attribution-NonCommercial-NoDerivs (CC BY-NC-ND)

\section{Document Version}

Peer reviewed version

Citation for published version (Harvard):

Makarova, AM, Pasta, S, Watson, G, Shackleton, C \& Epstein, EH 2017, 'Attenuation of UVR-induced vitamin $\mathrm{D}_{\text {}}$ synthesis in a mouse model deleted for keratinocyte lathosterol 5-desaturase', The Journal of Steroid Biochemistry and Molecular Biology. https://doi.org/10.1016/j.jsbmb.2017.03.017

Link to publication on Research at Birmingham portal

\section{General rights}

Unless a licence is specified above, all rights (including copyright and moral rights) in this document are retained by the authors and/or the copyright holders. The express permission of the copyright holder must be obtained for any use of this material other than for purposes permitted by law.

- Users may freely distribute the URL that is used to identify this publication.

- Users may download and/or print one copy of the publication from the University of Birmingham research portal for the purpose of private study or non-commercial research.

- User may use extracts from the document in line with the concept of 'fair dealing' under the Copyright, Designs and Patents Act 1988 (?)

- Users may not further distribute the material nor use it for the purposes of commercial gain.

Where a licence is displayed above, please note the terms and conditions of the licence govern your use of this document.

When citing, please reference the published version.

Take down policy

While the University of Birmingham exercises care and attention in making items available there are rare occasions when an item has been uploaded in error or has been deemed to be commercially or otherwise sensitive.

If you believe that this is the case for this document, please contact UBIRA@lists.bham.ac.uk providing details and we will remove access to the work immediately and investigate. 


\section{Accepted Manuscript}

Title: Attenuation of UVR-induced vitamin $\mathrm{D}_{3}$ synthesis in a mouse model deleted for keratinocyte lathosterol 5-desaturase

Authors: Anastasia M Makarova, Saloni Pasta, Gordon Watson, Cedric Shackleton, Ervin H Epstein Jr

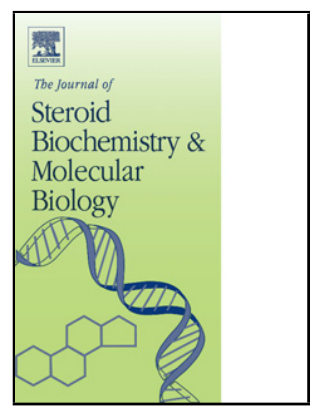

PII:

S0960-0760(17)30082-1

DOI: http://dx.doi.org/doi:10.1016/j.jsbmb.2017.03.017

Reference: SBMB 4917

To appear in: Journal of Steroid Biochemistry \& Molecular Biology

Received date: $\quad 10-8-2016$

Revised date: $\quad 27-2-2017$

Accepted date: $\quad$ 18-3-2017

Please cite this article as: Anastasia M Makarova, Saloni Pasta, Gordon Watson, Cedric Shackleton, Ervin H Epstein, Attenuation of UVR-induced vitamin D3 synthesis in a mouse model deleted for keratinocyte lathosterol 5-desaturase, Journal of Steroid Biochemistry and Molecular Biologyhttp://dx.doi.org/10.1016/j.jsbmb.2017.03.017

This is a PDF file of an unedited manuscript that has been accepted for publication. As a service to our customers we are providing this early version of the manuscript. The manuscript will undergo copyediting, typesetting, and review of the resulting proof before it is published in its final form. Please note that during the production process errors may be discovered which could affect the content, and all legal disclaimers that apply to the journal pertain. 


\section{Attenuation of UVR-induced vitamin $\mathrm{D}_{3}$ synthesis in a mouse model deleted for keratinocyte lathosterol 5-desaturase}

Anastasia M Makarova ${ }^{1}$, Saloni Pasta ${ }^{1}$, Gordon Watson ${ }^{1}$, Cedric Shackleton ${ }^{1,2}$, Ervin H Epstein, $\mathrm{Jr}^{1}$.

1. UCSF Benioff Children's Hospital Oakland Research Institute (CHORI), Oakland, California.

2. Institute of Metabolism and Systems Research (IMSR), College of Medical and Dental Sciences, University of Birmingham, Birmingham, UK.

Address for correspondence: Dr. E Epstein UCSF Benioff Children's Hospital Oakland Research Institute, 5700 Martin Luther King Jr. Way, Oakland, CA 94609, eepstein@chori.org, phone: 510-502-6144.

HighlightsSelective deletion of sterol $C 5$-desaturase $(S c 5 d)$ to prevent UVRinduced murine vitamin $D_{3}$ synthesis.

- Construction of a $S c 5 d$ floxed allele to allow conditional knockout in keratinocytes.

- Successful deletion proven by hair sterol analysis showing greatly increased content of SC5D substrates.

- $S c 5 d$ deletion allows investigation of the effects of UVR other than production of vitamin $\mathrm{D}_{3}$.

\section{Abstract}

The lower risk of some internal cancers at lower latitudes has been linked to greater sun exposure and consequent higher levels of ultraviolet radiation (UVR)-produced vitamin $D_{3}\left(D_{3}\right)$. To separate the experimental effects of sunlight and of all forms of $D_{3}$, a mouse in which UVR does not produce $D_{3}$ would be useful.

To this end we have generated mice carrying a modified allele of sterol C5desaturase $(S c 5 d)$, the gene encoding the enzyme that converts lathosterol to 7-dehydrocholesterol (7-DHC), such that $S c 5 d$ expression can be inactivated using the Cre/lox site-specific recombination system. By crossing to mice with tissue-specific expression of Cre or CreER ${ }^{2}$ (Cre/estrogen receptor), we generated two lines of transgenic mice. One line has 
constitutive keratinocyte-specific inactivation of $S c 5 d\left(S c 5 d^{k 14 K O}\right)$. The other line $\left(S c 5 d^{k 14 K O i}\right)$ has tamoxifen-inducible keratinocyte-specific inactivation of Sc5d.

Mice deleted for keratinocyte $S c 5 d$ lose the ability to increase circulating $D_{3}$ following UVR exposure of the skin. Thus, unlike in control mice, acute UVR exposure did not affect circulating $\mathrm{D}_{3}$ level in inducible $S c 5 d^{\mathrm{k} 14 \mathrm{KO} i}$ mice.

Keratinocyte-specific inactivation of $S c 5 d$ was proven by sterol measurement in hair - in control animals lathosterol and cholesta-7,24-dien-3 $\beta$-ol, the target molecules of SC5D in the sterol biosynthetic pathways, together constituted a mean of $10 \%$ of total sterols; in the conditional knockout mice these sterols constituted a mean of $56 \%$ of total sterols. The constitutive knockout mice had an even greater increase, with lathosterol and cholesta7,24 -dien-3 $\beta$-ol accounting for $80 \%$ of total sterols.

In conclusion, the dominant presence of the 7-DHC precursors in hair of conditional animals and the lack of increased circulating $D_{3}$ following exposure to UVR reflect attenuated production of the $D_{3}$ photochemical precursor 7-DHC and, consequently, of $\mathrm{D}_{3}$ itself. These animals provide a useful new tool for investigating the role of $\mathrm{D}_{3}$ in UVR-induced physiological effects and, more broadly, for investigations of the cholesterol synthetic pathway in the skin and other targeted tissues.

Keywords: Vitamin $D_{3}$ synthesis; lathosterol; sterol C5-desaturase (Sc5d); Sc5d knockout; Cre activation; sterol analysis; hair sterols

\section{INTRODUCTION}

In 1980 Cedric and Frank Garland first suggested that the latitudinal gradient of decreased cancer deaths at lower latitudes, known in particular for cancers of the colon and breast, might be due to the anti-cancer effects of sunlightproduced vitamin $\mathrm{D}_{3}\left(\mathrm{D}_{3}\right)^{l}$. Sparked in large part by their hypothesis, investigation of $\mathrm{D}_{3}$ and cancer has been an area of intense study with more than 9000 papers on this subject listed in PubMed. We describe here our success in constructing a transgenic mouse to facilitate study of the effects of ultraviolet radiation (UVR) independent of $\mathrm{D}_{3}$ production and its hydroxylated derivatives. Specifically, we have engineered a conditional mouse allele designed to allow tissue-specific deletion of the gene encoding sterol C5- 
desaturase $(S c 5 d)$, the enzyme responsible for the production of 7dehydrocholesterol (7-DHC).

Deficiency of SC5D (lathosterolosis) (OMIM 607330) joins DHCR7 deficiency (Smith-Lemli-Opitz syndrome) and 24-dehydrocholesterol reductase deficiency (desmosterolosis) as a disorder of post-squalene deficient cholesterol synthesis. Patients with lathosterolosis have elevated serum concentrations of lathosterol; four individuals with this condition have been reported, of whom only two survived infancy ${ }^{2,3}$. Surviving individuals in all three conditions have multiple congenital defects and developmental delays.

Similarly, global homozygous deletion of the mouse $S c 5 d$ gene produces stillborn pups with intrauterine growth retardation, craniofacial abnormalities (including cleft palate and micrognathia), and limb patterning defects $^{3}$. Many of the malformations (in humans and mouse models) are consistent with disruption during early vertebrate development of hedgehog signaling, which is influenced by cholesterol and its metabolites. Several different mechanisms for this influence have been described, among which the permissive and activating functions of direct binding of cholesterol to smoothened currently appear to be crucial ${ }^{4-7}$. Since global SC5D deficiency is lethal in mice, we have instead focused on constructing a model in which we use Cre/lox technology to achieve tissue- or stage-specific conditional inactivation, specifically deleting the $S c 5 d$ gene in keratinocytes. Herein, we report this construction and our characterization of mice lacking the $S c 5 d$ gene in keratinocytes, confirming the success of this approach by hair sterol analysis and by loss of ability to increase circulating $D_{3}$ following acute UVR exposure.

\section{MATERIALS AND METHODS}

\subsection{Generation of $S c 5 d$ embryonic stem (ES) cells and $S c 5 d^{\text {tm1a(EUCOMM)Hmgu }}$ mice}

We utilized the European Conditional Mouse Mutagenesis (EUCOMM) ${ }^{8}$ library of agouti C57BI/6N (JM8A3.N1) ${ }^{9}$ murine ES cells containing the PG00187_Z_8_B03 targeting vector integrated into the L1L2 Bact $P$ cassette inserted in chromosome 9 and targeting exon 4 of the Sc5D 
gene, causing a reading frame shift and thereby likely triggering nonsense mediated decay of the aberrant transcript (Fig. 2A). For details see www.knockout.org ${ }^{10}$. Mice were generated at the University of California Davis ${ }^{11}$ by blastocyst injection into C57BI/6N mice of three $\mathrm{ES}$ cell clones, one of which produced germline transmitting $S c 5 d^{\text {tm1a(EUCOMM)Hmgu }}$ founders (abbreviated as $S c 5 d^{\text {tm1a/+ }}$ ).

\subsection{Treatment groups and procedures}

\subsubsection{Mouse care}

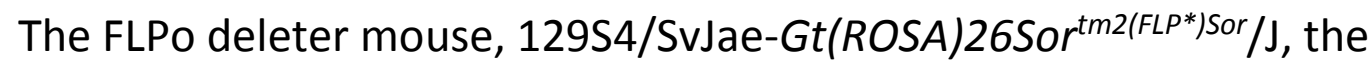
keratinocyte-specific constitutive Cre recombinase-expressing mouse, $\mathrm{Tg}(\mathrm{KRT} 14-\mathrm{Cre}) 1 \mathrm{Amc} / \mathrm{J}$, and the FVB/NJ mice were from The Jackson Laboratory (JAX, Sacramento, stock nos. 007844, 004782, and 001800 respectively). Tamoxifen-inducible keratinocyte-specific Cre recombinaseexpressing mice with a mutated ligand-binding domain for the human estrogen receptor (ER), K14-CreER ${ }^{2}$ were originally from Pierre Chambon (University of Strasbourg) ${ }^{12}$.

Mice were housed under standard conditions (fluorescent lighting 12 hours per day, room temperature $23^{\circ} \mathrm{C}$ to $25^{\circ} \mathrm{C}$, and relative humidity 45 to $55 \%$ ). Mice were maintained on standard diet (a normal $\mathrm{D}_{3} /$ normal minerals diet, $D_{3} 1500$ IU/kg, Ca 1\%, Phosphate 0.7\%; TD2018: Harlan, Madison, WI). We used 6 week-old mice for all studies unless otherwise specified in the text. For dietary studies mothers and enrollees were weaned onto and maintained on a $D_{3}$ depleted/normal minerals diet $\left(D_{3} 0 \mathrm{lU} / \mathrm{kg}\right.$, Ca $1 \%$, Phosphate $0.7 \%$; TD89123: Harlan, Madison, WI).

Animal care and use were in compliance with protocols approved by the Institutional Animal Care and Use Committee (IACUC) of Children's Hospital Oakland Research Institute (CHORI).

\subsubsection{Breeding and genotyping of mutant mice}

To create specific Cre recombinase-mediated deletions within the transgene and to manipulate the genetic background, a series of crosses, backcrosses 
and intercrosses were performed as summarized in Fig. 3. In all breeding the Cre transgene was inherited only from the father.

Upon treatment with tamoxifen at age 4 weeks $(100 \mu \mathrm{g} / \mathrm{mouse}$ by intraperitoneal (IP) injection once daily for three consecutive days) ${ }^{13}$, the CreER $^{2}$ construct translocated into the nucleus and deleted the floxed target region. We repeated a single tamoxifen IP injection monthly.

We confirmed deletion of the conditional Sc5d transgene by PCR using primer pairs located as indicated in Table 1 and described elsewhere ${ }^{14}$. We also confirmed the presence of transgenes encoding FLP, Cre and CreER ${ }^{2}$ recombinases by PCR (Fig. 2B). For all PCR reactions, thermocycling conditions consisted of 10 cycles of $15 \mathrm{~s}$ at $94^{\circ} \mathrm{C}, 30 \mathrm{~s}$ at $65^{\circ} \mathrm{C}$, and $40 \mathrm{~s}$ at $72^{\circ} \mathrm{C}$, decreased $1^{\circ} \mathrm{C} /$ cycle plus 30 cycles of $15 \mathrm{~s}$ at $94^{\circ} \mathrm{C}, 30 \mathrm{~s}$ at $55^{\circ} \mathrm{C}$, and $40 \mathrm{~s}$ at $72^{\circ} \mathrm{C}$. 
1. Generation of $S c 5 d /+$ mice from $E S$ cells

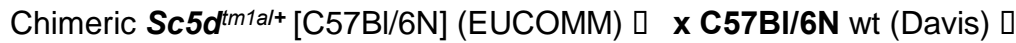

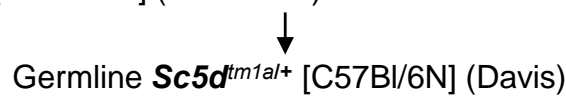

2. Introduction of $F V B / N$ background

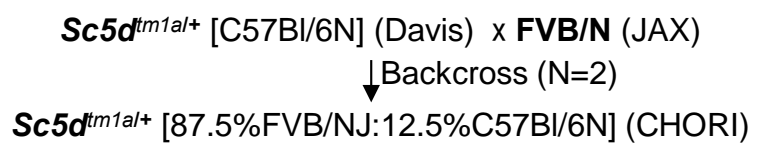

3. Breeding with FLPo strain to delete reporter

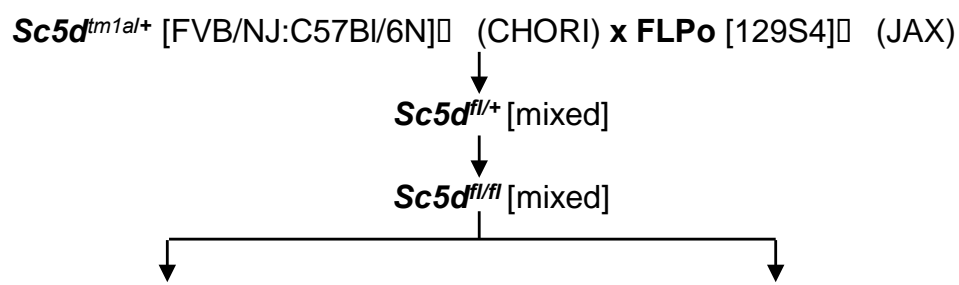

4a. Introduction of cCre to generate constitutive mice

4b. Introduction of iCre to generate inducible mice Sc5 $d^{f / f l f}[\mathrm{mixed}](\mathrm{CHORI}) \square \times \mathbf{~ T g}(\mathrm{KRT} 14-\mathrm{Cre}) 1 \mathrm{Amc} / \mathrm{J}$ [mixed] (JAX)
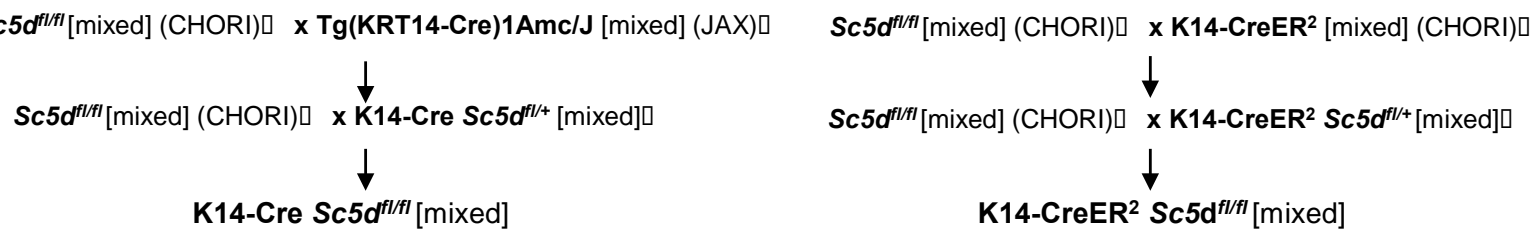

5. Introduction of FVB/N

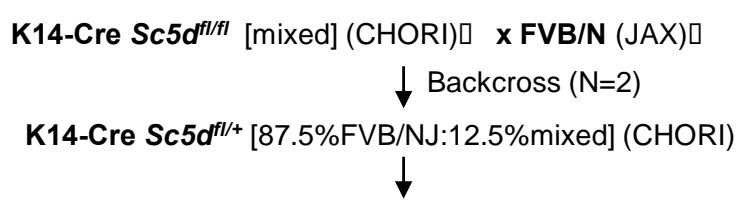

Constitutive Sc5dk14ko mice
K14-CreER ${ }^{2}$ Sc5d ${ }^{f l / f}[$ mixed] $(\mathrm{CHORI}) \square \times$ FVB/N $(\mathrm{JAX}) \square$

$\downarrow$ Backcross $(\mathrm{N}=5)$

K14-CreER ${ }^{2}$ Sc5 $d^{f /+}[$ 98.4\%FVB/NJ:1.6\%mixed] (CHORI)

Inducible Sc5dk14KOi mice

$<$ InlineImage $3>$ Figure 3. Breeding scheme for the generation of experimental animals. Scheme showing generation of constitutive $S c 5 d^{k 14 K O}$ mice and inducible $S c 5 d^{k l 14 K O i}$ mice. $S c 5 d^{\text {tmlalt }}$ chimeric mice were generated from ES cells and bred to produce mice with the engineered allele in the germline at the University of California Davis. At our institute (CHORI) $S c 5 d^{\text {mmla/+ }}$ mice were backcrossed twice onto the FVB/NJ background and then crossed to a FLPo mouse to delete the reporter and to generate $S c 5 d^{1 / 4}$ mice. The heterozygous floxed mice were intercrossed to produce $S c 5 d^{\text {t/fll }}$ mice, which were crossed to male K14-Cre- and K14-CreER ${ }^{2}$-expressing mice. In subsequent breedings, males heterozygous for the Cre transgene and heterozygous for the $S c 5 d$ allele $\left(S c 5 d^{7 /+}\right)$ were crossed with females homozygous for the conditional null $S c 5 d$ allele $\left(S c 5 d^{1 / f /}\right)$ to generate constitutive $S c 5 d^{k l 4 K O}$ mice and inducible $S c 5 d^{k 14 K O i}$ mice. The Cre transgene was inherited only from the father. Key: Round brackets ( ) indicate the source of the 
mice. Squared brackets [ ] indicate the strain of the mice, e.g. cCre, constitutive Cre-lox recombination and iCre, inducible Cre-lox recombination.

\subsubsection{UVR light source and treatment}

We used a UVR irradiation unit (R2025-bx-0012, Daavlin Co., Bryan, OH) with a bank of F40-T12 fluorescent tubes arranged in parallel, emitting UVB (280$315 \mathrm{~nm}$ ), and equipped with an electronic controller to regulate dosage. The dose was calibrated with an independent external UV light meter (925GOX96, Daavlin Co., Bryan, OH). UVR treatments were delivered consistently as described ${ }^{15}$. In brief, mice were shaved weekly and treated at the same time of the day. They were in a cage without bedding placed below the same areas of the lamp with a distance between the light source and mouse skin of $20 \mathrm{~cm}$.

To assess the effect of $S c 5 d$ deletion on circulating $D_{3}$ levels, 6 week-old mice ingesting a standard diet (TD2018) were used. Mice were treated with 350 $\mathrm{mJ} / \mathrm{cm}^{2}$ UVR (approximately 1 MED) on each of three alternate mornings, and blood was obtained 6 hours after the third treatment.

To study the impact of $S c 5 d$ deletion on physiological status of the mice, 6 to 20 week-old mice ingesting a $D_{3}$ depleted/normal minerals diet (TD89123) were treated with $350 \mathrm{~mJ} / \mathrm{cm}^{2}$ of UVR thrice weekly. All mice were examined daily for body weight and survival analysis.

\subsection{Hair sterol analysis by gas chromatography/mass spectrometry (GC/MS)}

We utilized hair for skin surface sterol analysis because our previous study ${ }^{16}$ showed that skin and hair sterol analysis gave equivalent results. Hair analysis is non-invasive and harmless.

We analyzed hair sterols as previously described ${ }^{16}$. In brief, hair $(4-6 \mathrm{mg})$ was sonically extracted with methanol:chloroform (2:1) for 16 hours following addition of stigmasterol as an internal standard. Following decanting, a secondary extraction for 2 hrs was undertaken. The extracts were combined and dried. To provide a total sterol fraction, samples were saponified in ethanolic potassium hydroxide at $55^{\circ} \mathrm{C}$. After addition of water, the samples were extracted with hexane, which then was evaporated. The samples were 
derivatized with bis-trimethylsilyl-trifluoroacetamide (BSTFA) to form the trimethylsilyl (TMS) derivatives. The derivatives finally were diluted with 500 $\mu \mathrm{l}$ of cyclohexane and transferred to autosampler vials for analysis by $\mathrm{GC} / \mathrm{MS}$. To minimize conversion of 7-DHC to previtamin $\mathrm{D}_{3}$, all tubes were protected from light with foil covers, and the whole procedure was conducted under minimum lighting conditions.

The GC/MS sterol analysis was essentially as previously described using an Agilent 5975 instrument (www.agilent.com). The sterols were separated on a non-polar DB-1 column. The GC temperature was programmed between 230 and $300^{\circ} \mathrm{C}$. The mass spectrometer was operated with electron impact (EI) ionization in SCAN mode. All sterols were quantified from total-ion-current (TIC) recordings against the internal standard stigmasterol assuming an equivalent response factor.

\subsection{Serum $D_{3}$ and 25-OH-D $D_{3}$ analysis}

We obtained blood by terminal cardiac puncture at the time of necropsy, and collected serum by centrifugation using amber tubes or tubes protected from light with foil covers. $\mathrm{D}_{3}$ and $25-\mathrm{OH}-\mathrm{D}_{3}$ levels were measured commercially (Heartland Assays LLC \& Metabolic Technologies, Inc.). Radioimmunoassay (RIA) was used to quantify $25-\mathrm{OH}-\mathrm{D}_{3}$. $\mathrm{D}_{3}$ was measured by LC/MS/MS using an Agilent 1290/6460 Series Triple Quadrupole System and a deuterated internal standard.

\subsection{Immunostaining}

We used standard immunostaining procedures ${ }^{13}$ with primary anti-Sc $5 \mathrm{dL}$ rabbit polyclonal (1:1200, Abcam) and secondary rabbit on rodent HRPpolymer (1:200, Biocare Medical) antibodies were used.

\subsection{PCR for $S c 5 d$ mRNA expression}

We collected RNA with the RNeasy Mini Kit (Qiagen). Reverse transcription was done with the Taqman reverse transcription kit (Applied Biosystems), and qPCR was done on cDNA with TaqMan premixed primer probes and reagents from Applied Biosystems. GAPDH was used as a normalization control for all experiments. We used 3 mice per group and 3 technical replicates per mouse.

\subsection{Statistical analysis}


Statistical analysis was carried out using GraphPad Prism 6 software (La Jolla, CA). For all measures, the significance of the difference in means between groups was evaluated by Student's t-test. We used the Log rank test to compare two Kaplan-Meier survival curves. All values are presented as mean \pm SD and those with $p \leq 0.05$ were considered to be statistically significant. Data was collected from multiple litters; mice from each litter were randomized into different treatment groups. Each data point represents biological replicates. All statistical analyses were done in consultation with the CHORI statistician G. Gildengorin.

\section{RESULTS AND DISCUSSION}

\subsection{Generation of conditional KO mice lacking $S c 5 d$ in keratinocytes}

Mice heterozygous for the $S c 5 d^{t m 1 a}$ conditional allele in the germline ${ }^{10}$ were viable and phenotypically grossly normal. However, homozygous $S c 5 d^{\mathrm{tm} 1 \mathrm{a} / \mathrm{tm} 1 \mathrm{a}}$ mice died in utero, indicating that the transgene, as expected, did not make functional enzyme protein. Deletion of the lac $Z$ cassette with FLP recombinase restored $S c 5 d$ gene function and left a target region flanked by loxP elements (i.e., floxed) (Fig. 2A). Both $S c 5 d^{f l /+}$ and $S c 5 d^{f l / f l}$ mice (without Cre) were viable, reproduced normally, exhibited a normal life span, and had no visible evidence of disrupted SC5D function or expression.

Using the Cre/loxP recombination system under the control of the keratin 14 gene promoter, which is active in basal cells of several stratified epithelia ${ }^{17}$, we developed two lines of conditional keratinocyte-specific transgenic mice, with constitutive or inducible deletion of $S c 5 d$ (as described in Methods). Constitutive $S c 5 d^{k 14 K O}$ mice were grossly normal and, like floxed or wild type mice, were able to nurse their pups, despite the known expression of keratin 14 in mammary glands ${ }^{18}$. The fur of constitutive $S c 5 d^{k 14 K O}$ mice was curly at age two weeks and scruffy in older mice (Fig. 2C). Inducible $S c 5 d^{k 14 K O i}$ mice were grossly normal, and, consistent with the less complete loss of SC5D in inducible $S c 5 d^{k 14 K O i}$ mice, their coats appeared normal. Older constitutive, but not inducible mice lose fur starting from the head at age 12 months and some became completely bald by age 18 months (Fig. 2C).

The degree of $S c 5 d$ mRNA expression in extracts of whole skin varied in the 
two strains of mice - in inducible $S c 5 d^{k 14 K O i}$ mice the reduction of $S c 5 d$ mRNA in extracts of whole skin was approximately $60 \%$ and in constitutive $S c 5 d^{k 14 k O}$ mice the reduction was approximately $75 \%$ of that in control mice.

\subsection{SC5D protein loss in keratinocytes}

We used immunohistochemistry (IHC) to assess the effects of gene deletion on SC5D protein levels. We found that in control mice irrespective of hair cycle keratinocytes express IHC-detectable SC5D, and this expression is lost from keratinocytes after Cre-mediated $S c 5 d$ deletion in constitutive and inducible $S c 5 d$ deleted mice (Fig. 4A). Some dermal cells express IHC-detectable SC5D during telogen but not during anagen in control mice, and dermal cells continued to express IHC-detectable SC5D protein in telogen in mice with $\mathrm{K} 14-\mathrm{CreER}^{2}$ treated with tamoxifen and in mice with K14-Cre (Fig. 4B).

\subsection{Effect of $S c 5 d$ knockout on UVR-induced changes in circulating vitamin $\mathbf{D}_{3}$}

To determine the effect of keratinocyte-specific loss of $S c 5 d$ on the ability of mice to make $D_{3}$ in the skin in response to UVR, we exposed shaved tamoxifen-treated $S c 5 d^{k 14 K O i}$ mice and control floxed $S c 5 d^{f l / f l}$ mice to $3 \times 350 \mathrm{~mJ} / \mathrm{cm}^{2}$ of UVR; untreated mice from the corresponding groups served as negative controls. UVR exposure increased circulating $D_{3}$ three-fold in control $S c 5 d^{f / / f l}$ mice (without Cre) (14.5 \pm 4.8 vs. $5.4 \pm$ $0.7 \mathrm{ng} / \mathrm{ml}, p=0.03$ ) but not in mice with inducible keratinocyte-specific deletion of $S c 5 d(6.1 \pm 1.0$ vs. $5.4 \pm 2.2 \mathrm{ng} / \mathrm{ml}, p=0.7)$ (Fig. $4 \mathrm{C})$. This result proves significant $S c 5 d$ deletion and consequent loss of ability to release UVR-produced $D_{3}$ from the skin into the circulation.

\subsection{SC5D-dependent changes in hair sterols}

Representative chromatograms (TIC) from hair of $S c 5 d$-deleted mice (inducible $S c 5 d^{k 14 K O i}$ mice) and control $S c 5 d^{f / f f}$ mice (lacking CreER ${ }^{2}$ ) are shown in Fig. $5 \mathrm{~A}, \mathrm{~B}$, with quantification in Table 2 . Six sterols could be detected and quantified readily, but the levels of 7-DHC and 7-DHD were each below $1 \%$ of total sterols and therefore could not be quantified precisely (Table 2 ). We confirmed the structure of all sterols by comparing 
their mass spectra and retention times with authentic compounds; full mass spectra of these sterols were shown in our previous communication ${ }^{16}$.

We found in control floxed mice (lacking Cre) very low levels of SC5D substrate sterols (Fig 5A), similar to those we reported previously in mice with wild type SC5D expression ${ }^{16}$, indicating that the addition of loxP sequences did not significantly inhibit the activity of the gene. By contrast, we found in hair sterols of mice with active Cre (inducible $S c 5 d^{k 14 K O i}$ mice or constitutive $S c 5 d^{k 14 K O}$ mice) a marked increase in the levels of the $S c 5 d$ substrates lathosterol and cholesta-7,24-dien-3 $\beta$-ol, indicating reduction in their conversion to 7-DHC and 7-DHD, respectively (for ref. see Fig. 1). The histograms in Fig. $5 \mathrm{C}$ show for $S c 5 d^{k 14 K O i}$ mice and control $S c 5 d^{f / f f l}$ (lacking Cre) mice the quantitation of individual sterols among the total sterols. Consistent with greater efficiency of deletion of $S c 5 d$ mRNA, constitutively active K14Cre gave a greater increase in lathosterol and cholesta-7,24-dien-3 $\beta$-ol than did inducible K14-CreER ${ }^{2}$. Cholesterol is reduced in amount, consistent with a reduction in levels of its precursors. The near equivalence of desmosterol and cholesterol in hair of normal mice is interesting and was noted in our previous communication ${ }^{16}$. This implies equivalence of the Bloch and Kandutsch pathways as well as relative deficiency of desmosterol 24reductase.

\subsection{Impact of $S c 5 d$ knockout on physiological status of the mice}

We investigated whether keratinocyte-specific $S c 5 d$ deletion has a clinically-detectable effect on the mice by determining longevity rescue in mice on a D-depleted diet. We generated D-depleted mice by feeding mothers and their offspring a $\mathrm{D}_{3}$ depleted/normal minerals diet (TD89123), a diet lacking the high, "rescue" levels of minerals generally used to maintain health in the context of D-depletion. At age 6 weeks we started UVR treatment $\left(350 \mathrm{~mJ} / \mathrm{cm}^{2}\right.$ thrice weekly) of mice to restore $\mathrm{D}_{3}$ levels. We compared the survival of D-depleted control $S c 5 d^{f l f l}$ mice lacking Cre versus survival of D-depleted mice with keratinocytespecific Sc5d deletion, - Sc $5 d^{k 14 K O i}$. As expected, UVR -treated control $S c 5 d^{f l f l}$ mice (lacking CreER ${ }^{2}$ ) lived significantly longer than did UVRtreated $S c 5 d^{k 14 K O i}$ mice with conditional deletion of $S c 5 d$ in keratinocytes (Fig. 6).

\section{CONCLUSION}


Clearly keratinocyte Cre activation has a profound effect on $S c 5 d^{\text {k14ko }}$ mice, causing decreased $S c 5 d$ mRNA (as detected by qPCR), decreased SC5D protein (as detected by $\mathrm{HC}$ ), decreased circulating vitamin $\mathrm{D}_{3}$ following acute UVR exposure, and increased concentrations of SC5D substrates in the hair sterols produced by K14-expressing keratinocytes (i.e. those destined to become sebaceous gland cells). As expected from published data on the relative efficacies of the two K14-Cre alleles, the effect on hair sterols was greater (i.e., a larger percentage of precursors present) following deletion with the constitutive K14-Cre than that obtaining with the inducible K14-CreER ${ }^{2}$ allele ${ }^{16,19}$.

These mice have been useful in our studies of the D-dependency of the effect of UVR on basal cell carcinoma induction in Ptch1 ${ }^{+/-}$mice (A Makarova et al, submitted) and thus can provide valuable means, not available by other approaches, to distinguish whether or not specific effects of UVR are D-dependent. In addition they should be useful in studies of local cholesterol synthesis. Furthermore, our studies are an example of the value of the Knockout Mouse Project (KOMP/EUKOMM) ${ }^{8}$, even in the CRISPR era, in providing off-the-shelf ES cells from their library with mutations targeted to a gene of interest.

\section{Acknowledgements}

We wish to thank Pieter de Jong at CHORI for helpful advice on the development of mice with the $S c 5 d$ floxed allele, Sasha Wirth at the University of California Davis for helpful advice and for the breeding of our mutant mice, and Ginny Gildengorin at CHORI for discussions on statistical analysis. Supported by NIH R01CA142879 (E Epstein), NIH HD053036 (C Shackleton, G Watson), 10A103 American Institute for Cancer Research (E Epstein) and UC Berkeley/CHORI T32 training grant in Tumor Biology (A Makarova).

Notes: *K14Cre primers and PCR conditions can be obtained from The Jackson Laboratory (JAX, Sacramento).

Notes: *\#556 is not included in estimation of the means as it appears to be an outlier - based on genotyping it is reported as mutant, but appears closer to WT, based on sterol percentage by GC-MS.

** DHC and 7-DHD were below the limit of accurate measurement, and are thus not included in 
the analysis.

\section{References}

1. Garland, C. F., and Garland, F. C. (1980) Do sunlight and vitamin D reduce the likelihood of colon cancer?, International journal of epidemiology 9 , 227-231.

2. Brunetti-Pierri N, C. G., Rossi M, Ferrari P, Balli F, Rivasi F, Annunziata I, Ballabio A, Russo AD, Andria G, Parenti G. (2002) Lathosterolosis, a novel multiple-malformation/mental retardation syndrome due to deficiency of 3beta-hydroxysteroid-delta5-desaturase., Am J Hum Genet 71, 952-958.

3. Krakowiak, P. A., Wassif, C. A., Kratz, L., Cozma, D., Kovarova, M., Harris, G., Grinberg, A., Yang, Y., Hunter, A. G., Tsokos, M., Kelley, R. I., and Porter, F. D. (2003) Lathosterolosis: an inborn error of human and murine cholesterol synthesis due to lathosterol 5-desaturase deficiency, Hum Mol Genet 12, 1631-1641.

4. Koide, T., Hayata, T., and Cho, K. W. (2006) Negative regulation of Hedgehog signaling by the cholesterogenic enzyme 7-dehydrocholesterol reductase, Development 133, 2395-2405.

5. Lauth, M., Rohnalter, V., Bergstrom, A., Kooshesh, M., Svenningsson, P., and Toftgard, R. (2010) Antipsychotic drugs regulate hedgehog signaling by modulation of 7-dehydrocholesterol reductase levels, Mol Pharmacol 78, 486-496.

6. Myers BR, S. N., Chong YC, Kim J, Belani JD, Rychnovsky S, Bazan JF, Beachy PA. (2013) Hedgehog pathway modulation by multiple lipid binding sites on the smoothened effector of signal response., Dev Cell. 26, 346-357.

7. Riobo NA. (2012) Cholesterol and its derivatives in Sonic Hedgehog signaling and cancer., Curr Opin Pharmacol. 12, 736-741.

8. https://www.komp.org.

9. Pettitt, S. J., Liang, Q., Rairdan, X. Y., Moran, J. L., Prosser, H. M., Beier, D. R., Lloyd, K. C., Bradley, A., and Skarnes, W. C. (2009) Agouti C57BL/6N embryonic stem cells for mouse genetic resources, Nature methods 6, 493-495.

10. https://www.i-dcc.org/imits/targ_rep/alleles/4680/vector-image.

11. https://mbp.mousebiology.org.

12. Indra, A. K., Li, M., Brocard, J., Warot, X., Bornert, J.M., Gerard, C., Messaddeq, N., Chambon, P., and Metzger, D. (2000) Targeted somatic mutagenesis in mouse epidermis., Horm. Res. 54, 296-300. 
13. Wang, G. Y., Wang, J., Mancianti, M. L., and Epstein, E. H., Jr. (2011) Basal cell carcinomas arise from hair follicle stem cells in ptch1(+/-) mice, Cancer Cell 19, 114-124.

14.

https://www.komp.org/pdf/Genotyping_of_KOMP_CSD_targeted_all eles_Protocol.pdf.

15. So, P. L., Lee, K., Hebert, J., Walker, P., Lu, Y., Hwang, J., Kopelovich, L., Athar, M., Bickers, D., Aszterbaum, M., and Epstein, E. H., Jr. (2004) Topical tazarotene chemoprevention reduces Basal cell carcinoma number and size in Ptch1+/- mice exposed to ultraviolet or ionizing radiation, Cancer Res 64, 4385-4389.

16. Serra, M., Matabosch, X., Ying, L., Watson, G., and Shackleton, C. (2010) Hair and skin sterols in normal mice and those with deficient dehydrosterol reductase (DHCR7), the enzyme associated with Smith-Lemli-Opitz syndrome, The Journal of steroid biochemistry and molecular biology 122, 318-325.

17. Vassar, R., Rosenberg, M., Ross, S., Tyner, A., and Fuchs, E. (1989) Tissuespecific and differentiation-specific expression of a human K14 keratin gene in transgenic mice, Proc Natl Acad Sci U S A 86, 1563-1567.

18. Mikaelian, I., Hovick, M., Silva, K. A., Burzenski, L. M., Shultz, L. D., Ackert-Bicknell, C. L., Cox, G. A., and Sundberg, J. P. (2006) Expression of terminal differentiation proteins defines stages of mouse mammary gland development, Veterinary pathology 43, 36-49.

19. Yang SH, C. S., Yin L, Tu Y, Hu Y, Yoshinaga Y, de Jong PJ, Fong LG, Young SG. (2011) An absence of both lamin B1 and lamin B2 in keratinocytes has no effect on cell proliferation or the development of skin and hair., Hum Mol Genet. 20, 3537-3544. 

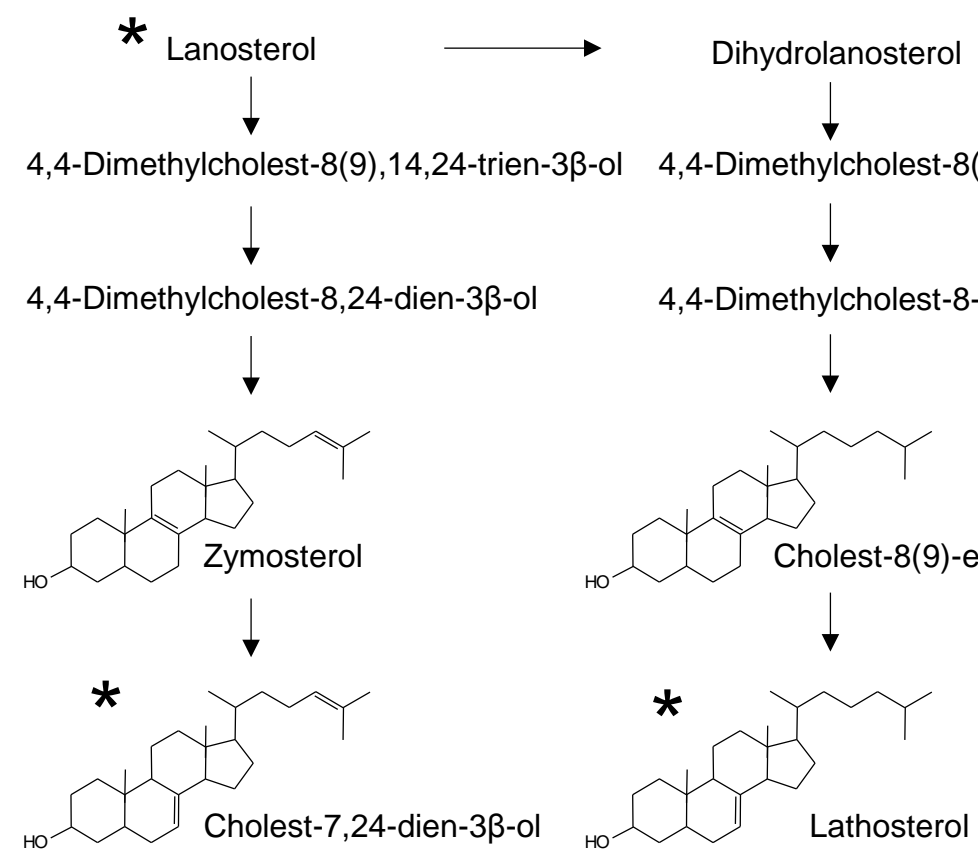

4,4-Dimethylcholest-8(9),14-dien-3ß-ol
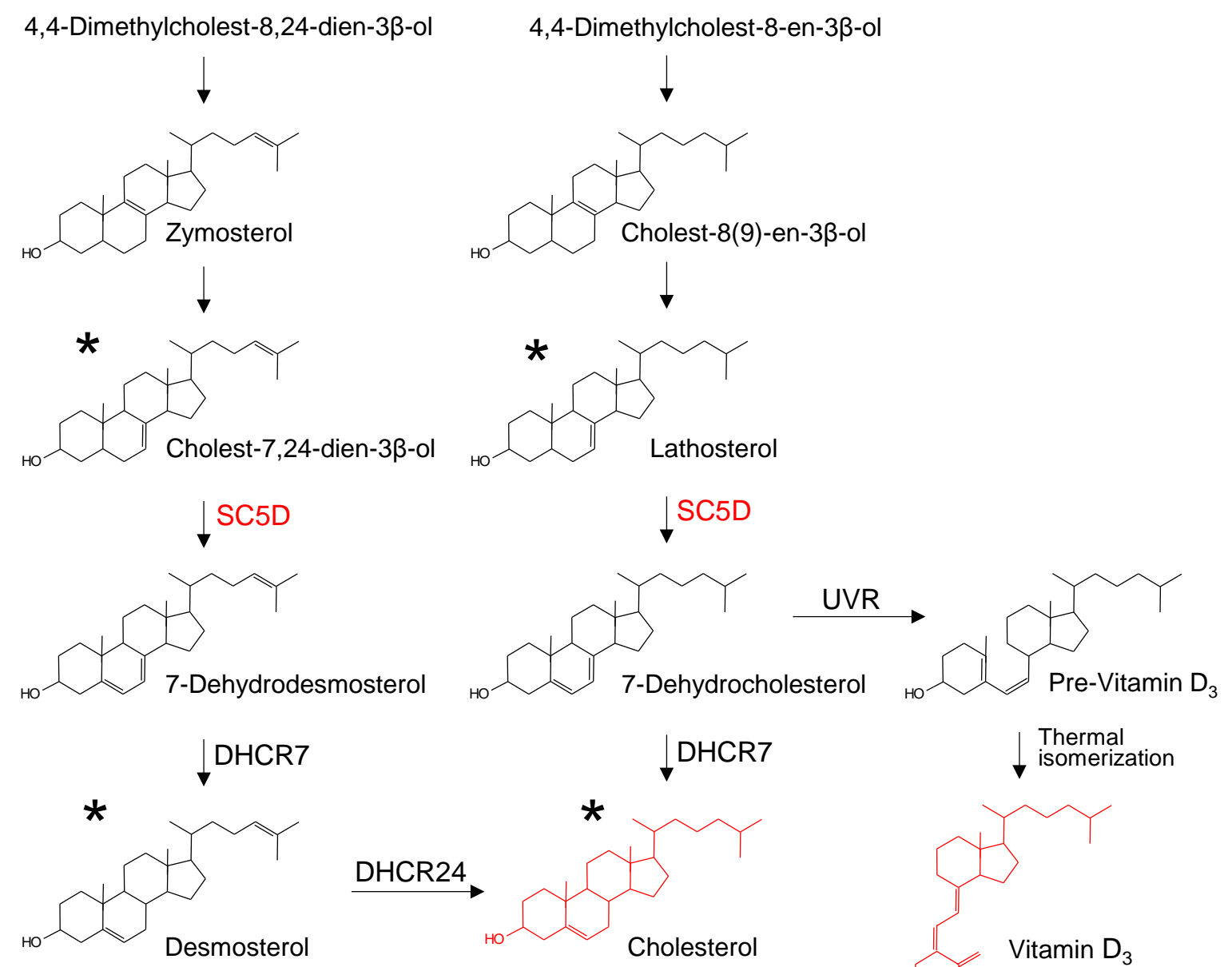

$\downarrow$ SC5D

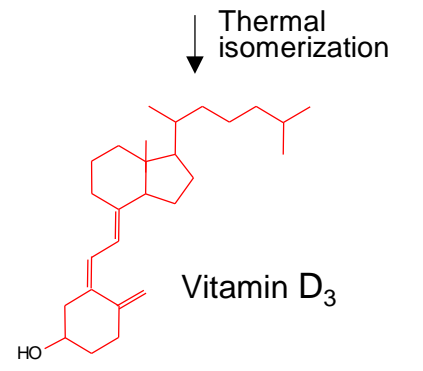

$<$ Inlinelmage1>

Figure 1. Post squalene cholesterol and vitamin $D_{3}$ synthesis. Two synthetic pathways of cholesterol are shown, the Bloch pathway at left and the KandutschRussell pathway at right. Vitamin $D_{3}$ synthesis in the skin is shown at right. The sterols marked with asterisks were identified and measured in this study. 
A
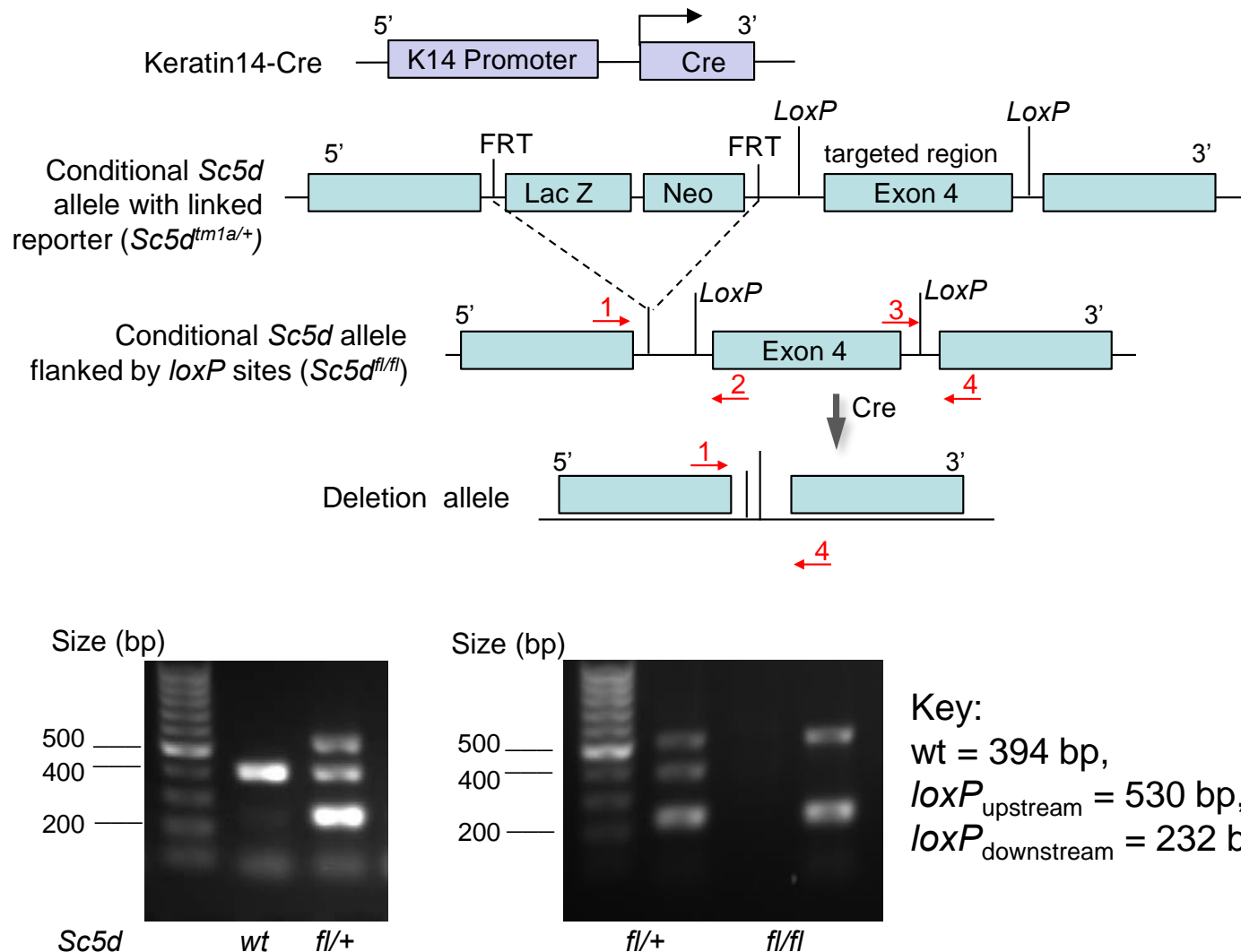

Key:

wt $=394 \mathrm{bp}$,

lox $P_{\text {upstream }}=530 \mathrm{bp}$,

$\operatorname{lox} P_{\text {downstream }}=232 \mathrm{bp}$

C

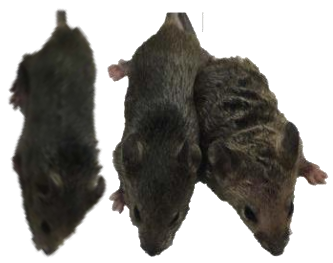

$\operatorname{Sc5} d^{f / f l l} \operatorname{Sc5} d^{k 14 K O i} \operatorname{Sc5} d^{k 14 K O}$

2 weeks old

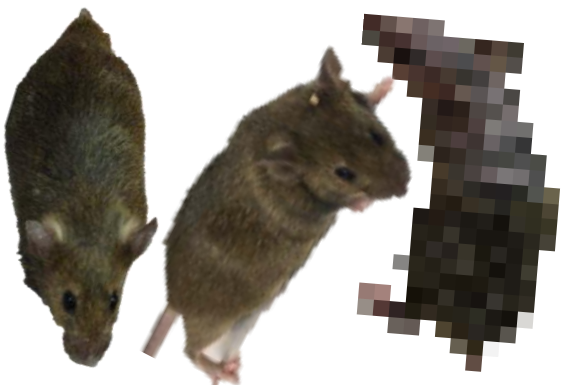

$S c 5 d^{f / f f l} S c 5 d^{k 14 k O i} S c 5 d^{k 14 k O}$

12 months old

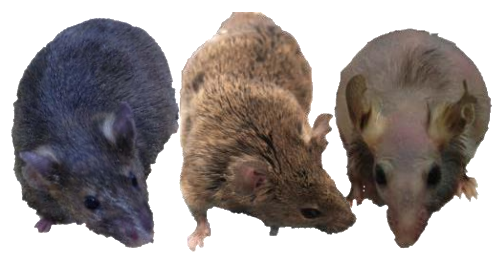

$S c 5 d^{f / f f l} \quad S c 5 d^{k 14 K O i} \quad S c 5 d^{k 14 K O}$

$<$ Inlinelmage2>

Figure 2. Characterization of the floxed $S c 5 d$ conditional mice. A.

Schematic of keratinocyte-specific deletion of the conditional vector. The targeted allele contains a lacZ trapping cassette and a promoter-driven Neo cassette inserted into the intron of the gene and disrupting gene function. The reporter was deleted by crossing mice with FLPo deleter mouse (stock 
no. 007844 , JAX, Sacramento). The resulting $S c 5 d$ allele has loxP sites flanking exon 4 that was excised by Cre recombinase to generate a loss-offunction allele. Restriction sites and the location of the PCR primers are indicated. B. Representative PCR results (using primers 1-4) of DNA from mice containing the WT $S c 5 d$ allele and floxed $S c 5 d$ allele are shown. Confirming the FLP-mediated deletion of $L a C Z$ and Neo and the presence of the upstream loxP site, the primers 1 and 2 yield the $530 \mathrm{bp}$ product. The $232 \mathrm{bp}$ product of primers 3 and 4 confirmed the presence of the downstream loxP site. Primers 1 and 2 produce a 394 bp product from the WT allele. DNA was extracted from tail snips. C. Representative images of the generated mice. At age two weeks only $S c 5 d^{k 14 K O}$ mice had curly hair. Older $S c 5 d^{k 14 K O}$, but not inducible $S c 5 d^{k 14 K O i}$ mice lose fur starting from the head at age 12 months, and some became completely bald by age 18 months. 

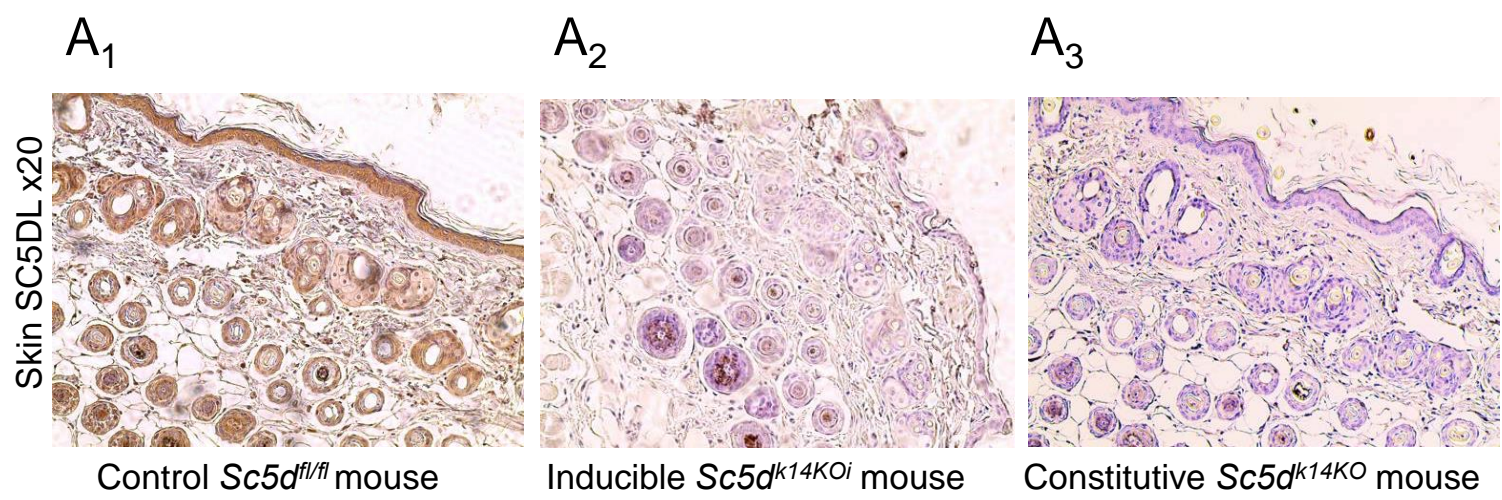

Note: $A_{1}-A_{3}$ - anagen phase
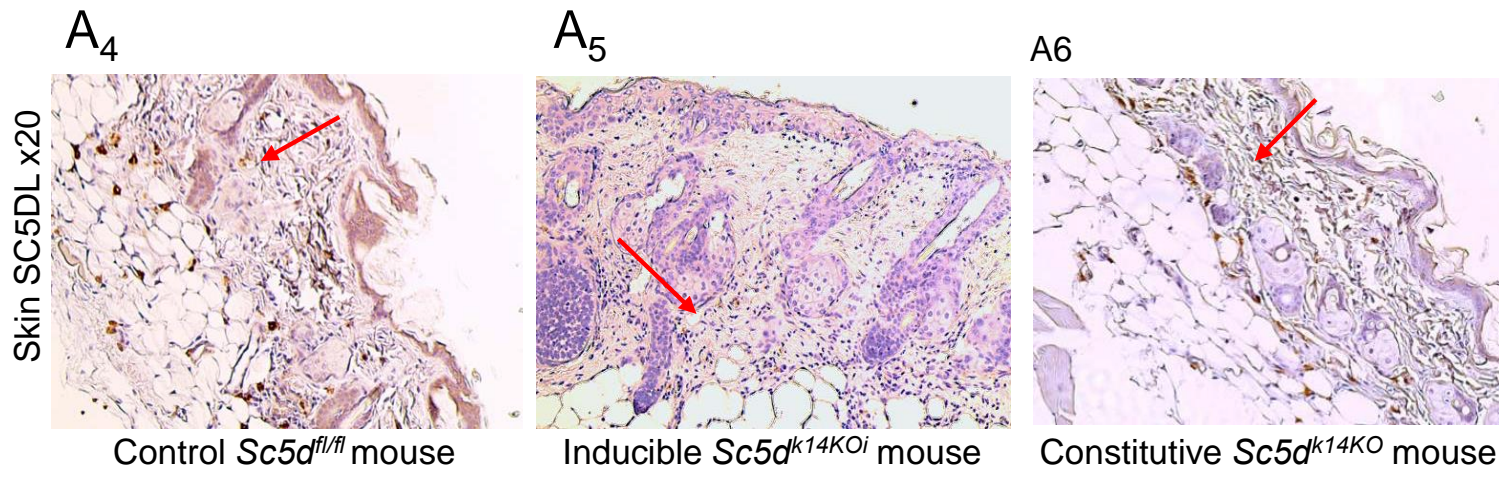

Note: $A_{4}-A_{6}$ - telogen phase

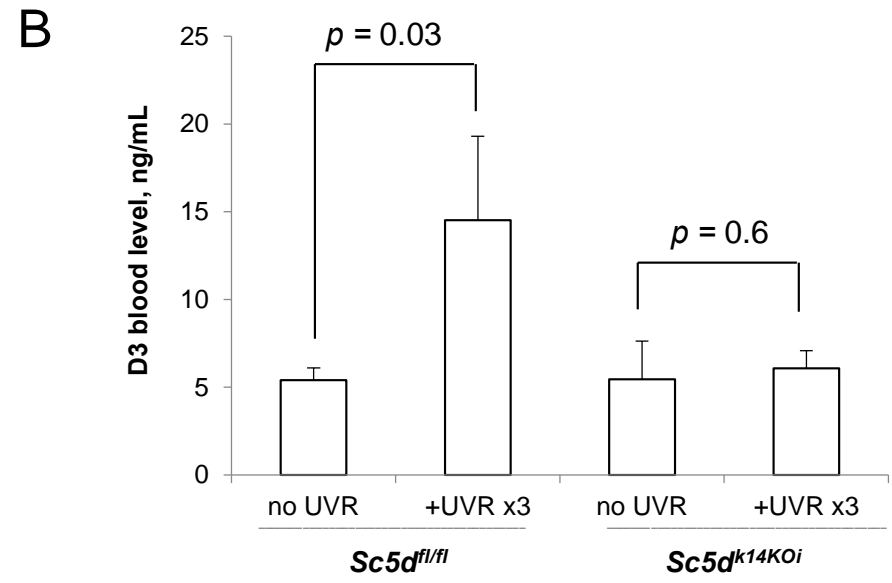

\section{$<$ Inlinelmage4>}

Figure 4. Confirmation of SC5D loss in keratinocytes by IHC and by measuring vitamin $\mathbf{D}_{3}$ level in the blood. A. Skin samples from anagen skin (upper panels, $A_{1-}$ 3 ) and telogen skin (lower panels, $A_{4-6}$ ) from 20 week-old control (no Cre) floxed mice $\left(A_{1,4}\right)$ inducible $S c 5 d^{k 14 K O i}\left(A_{2,4}\right)$ and constitutive $S c 5 d^{k 14 K O}$ mice $\left(A_{3,6}\right)$. Note 
strong brown staining of keratinocytes in control floxed mice in anagen phase $\left(A_{1}\right)$ and of keratinocytes + dermal cells in control mice during telogen phase $\left(A_{4}\right)$, deletion of keratinocyte staining in Cre-containing mice $\left(A_{2}, 3,5,6\right)$, and limitation of staining of dermal cells to telogen phase if $C r e$ is activated $\left(A_{5,6}\right.$ vs. $\left.A_{2,3}\right)$. All skin samples were fixed, sectioned, stained for SC5DL, and counterstained with hematoxylin and eosin. $\mathrm{N}=6$ mice per group, 10-15 tissue sections per mouse were analyzed. Arrows indicate SC5D positive cells in the dermis. B. UVR exposure $\left(3 x\right.$ with $\left.350 \mathrm{~mJ} / \mathrm{cm}^{2}\right)$ increased the circulating $D_{3}$ level in control floxed $S c 5 d^{f / f l}$ mice lacking CreER ${ }^{2}$, but not in inducible $S c 5 d^{k 14 K O i}$ mice, confirming $S c 5 d$ deletion and consequent loss of ability to elevate circulating $D_{3}$ after UVR treatment, $n=3$ mice/group, mean \pm SD. 
A

B
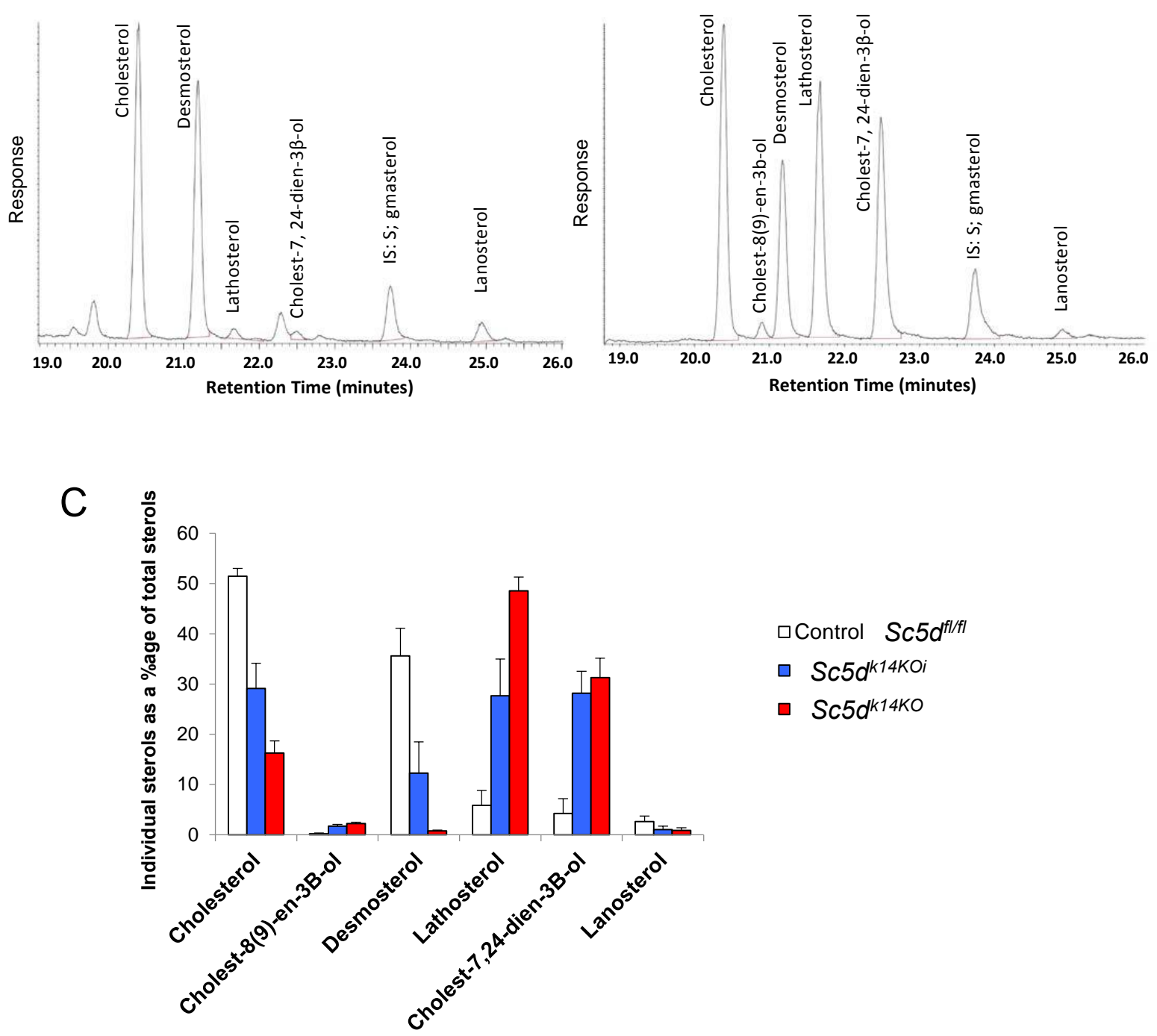

$\square$ Control $S c 5 d^{f / f f l}$

- $\operatorname{Sc} 5 d^{k 14 K O i}$

- Sc5dk14KO

$<$ Inlinelmage5 $>$

Figure 5. Chromatograms of hair sterols. Panels A and B. Segments of total-ioncurrent (TIC) chromatograms of hair sterols (as TMS derivatives) of control Sc5 $d^{f l / f l}$ mice lacking $\operatorname{CreER}^{2}(\mathbf{A})$ and inducible $S c 5 d^{k 14 K O i}$ mice (B). Panel C, individual hair sterols as a percent of measured sterols: sterol analysis from hair of control $S c 5 d^{f l / f l}$ mice lacking $\operatorname{CreER}^{2}$ ( $n=4$ mice), constitutive $S c 5 d^{k 14 K O}$ mice ( $n=4$ mice) and inducible $S c 5 d^{k 14 K O i}$ mice ( $n=5$ mice). Data represent biological replicates and are shown as the mean \pm SD. 


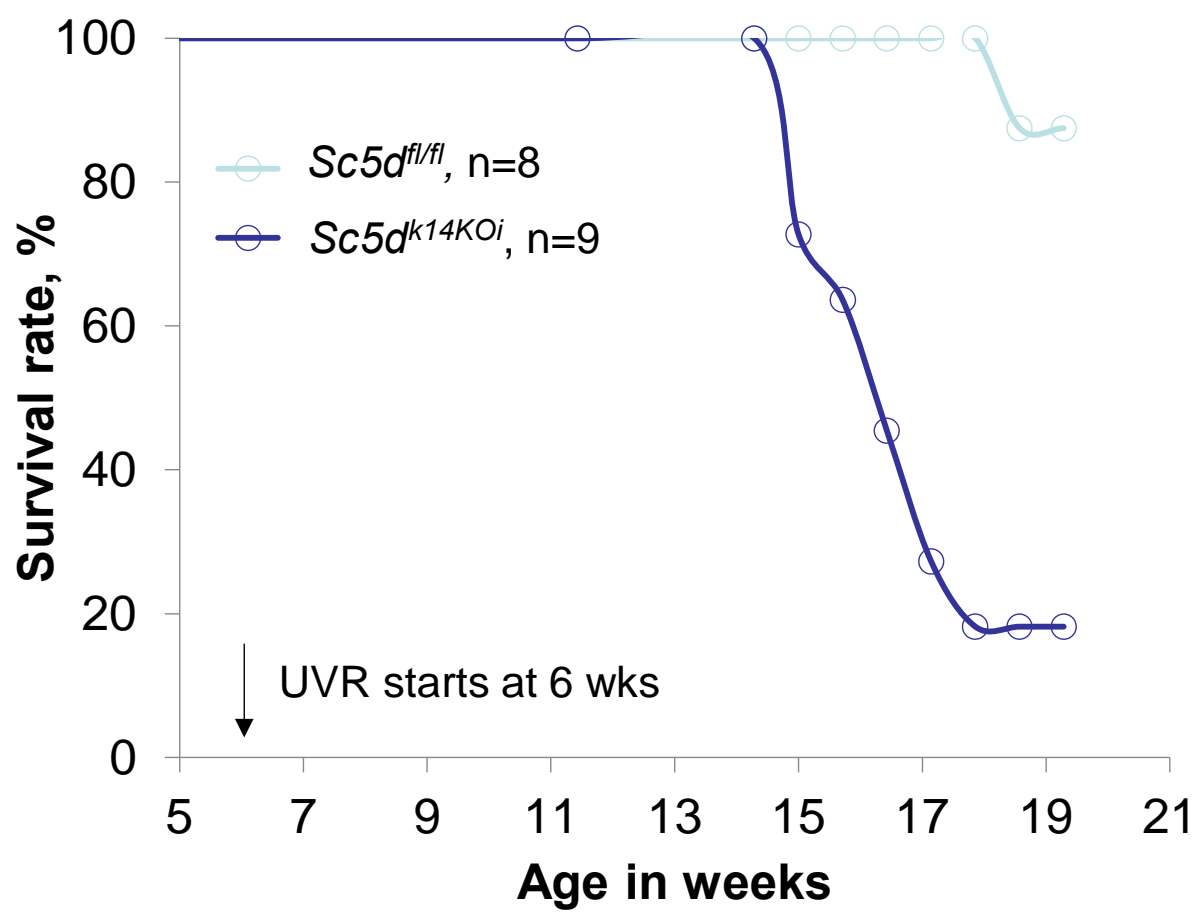

$<$ Inlinelmage6 $>$

Figure 6. Kaplan-Meier analysis of overall survival. D-depleted mice were generated by feeding mothers and their offspring a $D_{3}$ depleted/normal minerals $\operatorname{diet}\left(\right.$ TD89123). At weaning $S c 5 d^{f l / f l}$ mice were enrolled into two groups according to genotype: with and without K14-CreER ${ }^{2}$. At age 4 weeks mice of both groups were treated with tamoxifen to generate control $S c 5 d^{f / f l}$ and $S c 5 d^{k 14 K O i}$ mice. UVR was started at age 6 weeks and continued in surviving mice until age 20 weeks, 350 $\mathrm{mJ} / \mathrm{cm}^{2}$ thrice weekly. Control $=S c 5 d^{f / f l}$ mice lacking CreER ${ }^{2}$. Conditional deletion of Sc5d significantly decreased ( $p \leq 0.05$, log-rank test) the survival rate of UVRtreated female mice on $a D_{3}$ depleted/normal minerals diet born to mothers weaned onto the same diet; $n=8$ - 9 mice/group.

Table 1. PCR primers used in the Study.

\begin{tabular}{|lll|}
\hline Primer name & Primer sequence \\
\hline & Sc5d gene specific primers & \\
\hline Primer 1: CSD-gene-F & Ctctctagcttttgcatgctgacagg \\
\hline Primer 2: CSD-gene-ttR & Gctgttaagctcacttttcaggtccac \\
\hline Primer 4: CSD-gene-R & Gcaagaccctgtcaagaaagaagg \\
\hline & Sc5d cassette primers & \\
\hline
\end{tabular}




\begin{tabular}{|c|c|c|}
\hline \multicolumn{2}{|l|}{ Primer 3: CSD-lox F } & Gagatggcgcaacgcaattaatg \\
\hline \multicolumn{2}{|l|}{ CSD-lacF } & Gctaccattaccagttggtctggtgtc \\
\hline \multicolumn{2}{|l|}{ CSD-NeoF } & Gggatctcatgctggagttcttcg \\
\hline \multicolumn{3}{|c|}{ K14-CreER² primers } \\
\hline K14-CreER ${ }^{2} 3^{\prime}$ & & Tgcggtgctaaccagcgtttt \\
\hline K14-CreER ${ }^{2} 5^{\prime}$ & & Catgttcagggatcgccagg \\
\hline Genotypes & Primer pairs & Amplicon size, bp \\
\hline$S c 5 d w t$ & Primers 1 and 2 & 394 \\
\hline Floxed Pre Cre & CSD-NeoF and CSD-gene-ttR & 556 \\
\hline LacZ allele Post $C r e$ & CSD-lacF and CSD-gene-R & 530 \\
\hline Sc5d floxed Post Flp & Primers 1 and 2 & 530 \\
\hline lox $P_{\text {downstream }}$ region & Primers 3 and 4 & 232 \\
\hline Post Flp then Cre & Primer 1 and CSD-gene- $R$ & 553 \\
\hline
\end{tabular}

Table 2. Individual hair sterols as a percentage of total measured sterols.

\begin{tabular}{|c|c|c|c|c|c|c|c|c|c|c|c|c|c|c|}
\hline \multirow{3}{*}{$\begin{array}{l}\text { Genotype } \\
\text { Mouse \# }\end{array}$} & \multicolumn{7}{|c|}{ WT } & \multicolumn{7}{|c|}{ Mutant } \\
\hline & \multicolumn{5}{|c|}{ \% sterols } & \multirow[b]{2}{*}{$\begin{array}{l}\text { Avg } \\
\%\end{array}$} & \multirow[b]{2}{*}{ S.D. } & \multicolumn{5}{|c|}{ \% sterols } & \multirow[b]{2}{*}{$\begin{array}{l}\text { Avg } \\
\%\end{array}$} & \multirow[b]{2}{*}{ S.D. } \\
\hline & $\# 153$ & $\# 434$ & $\# 508$ & $\# 518$ & $\# 556$ & & & $\# 118$ & $\# 442$ & $\# 451$ & $\# 465$ & $\# 484$ & & \\
\hline Cholesterol & 49.83 & 53.58 & 51.40 & 51.12 & 45.98 & 51.48 & 1.55 & 29.67 & 34.00 & 23.16 & 33.93 & 25.00 & 29.15 & 4.99 \\
\hline $\begin{array}{l}\text { Cholest-8(9)- } \\
\text { en-3b-ol }\end{array}$ & 0.00 & 0.27 & 0.16 & 0.34 & 0.76 & 0.19 & 0.15 & 1.43 & 1.57 & 2.26 & 1.32 & 1.87 & 1.69 & 0.38 \\
\hline Desmosterol & 42.59 & 31.82 & 37.29 & 30.64 & 33.30 & 35.58 & 5.50 & 17.76 & 13.92 & 2.32 & 16.72 & 10.70 & 12.28 & 6.21 \\
\hline Lathosterol & 1.77 & 5.62 & 7.24 & 8.73 & 9.36 & 5.84 & 2.99 & 25.56 & 23.21 & 36.58 & 19.23 & 33.78 & 27.67 & 7.29 \\
\hline $\begin{array}{l}\text { Cholest-7,24- } \\
\text { dien-2b-ol }\end{array}$ & 1.58 & 6.15 & 1.91 & 7.38 & 8.75 & 4.26 & 2.95 & 24.38 & 26.16 & 35.67 & 26.94 & 27.79 & 28.19 & 4.37 \\
\hline Lanosterol & 4.22 & 2.57 & 2.00 & 1.79 & 1.85 & 2.64 & 1.10 & 1.21 & 1.15 & 0.00 & 1.86 & 0.86 & 1.02 & 0.68 \\
\hline
\end{tabular}

